\title{
Methane Sulphonic Acid is Green Catalyst in Organic Synthesis
}

\author{
PRAMOD KULKARNI \\ Department of Chemistry, Hutatma Rajguru Mahavidyalaya Rajgurunagar Pune - 410505, India. \\ ${ }^{*}$ Corresponding E-mail: pramodskulkarni3@gmail.com \\ http://dx.doi.org/10.13005/ojc/310154
}

(Received: December 05, 2014; Accepted: January 10, 2015)

\begin{abstract}
Methane sulphonic acid is an alkanesulphonic acid and its chemical formula is $\mathrm{CH}_{3} \mathrm{SO}_{3} \mathrm{H}$. MSA is a strong acid having $\mathrm{pKa}=1.9$ and completely ionized in $0.1 \mathrm{M}$ in an aqueous solution and has small affinity to oxidize organic compounds, less corrosive and toxic than other mineral acids. MSA is also biodegradable and not evolve toxic gases. Therefore MSA is considered as green acid. Therefore its use in organic synthesis attracts many chemists to use in organic synthesis. In this review we described the MSA catalyzed organic transformation.
\end{abstract}

Key words: Methane sulphonic acid, green, catalyst, organic reactions.

\section{INTRODUCTION}

\section{Physical properties of Methane Sulphoic Acid} Methane sulphonic acid is a clear colourless liquid available as a $70 \%$ solution in water and anhydrous form. The structure of methane sulphonic acid lends itself to many catalytic reactions, due to its high acid strength $(\mathrm{pKa}=-1.9)$ and low molecular weight $(96.0 \mathrm{~g} / \mathrm{mol})$.

Methane Sulphonic Acid is Green Acid Catalysts

i. It is easy to handle methane sulphonic acid as liquid and can be recyclized.

ii. It has low $L_{50}$ and biodegradable forming sulphate and $\mathrm{CO}_{2}$.

iii. Methane sulphonic acid is considered to be natural product and is part of the natural sulphur.

iv. It is less corrosive and toxic than other mineral acids.

Due to these properties methane sulphonic acid making an environmentally benign material ${ }^{1}$.

Applications of Methane sulphonic acid as catalyst in organic synthesis

1. H. Naeimi et. al used methane sulphonic acid as catalyst for regioselective route for Direct Ortho-Acylation of Phenols and Naphthols under Microwave condition².

2. M. Heravi et. al use MSA as catalyst for One- 
pot synthesis of 2-Amino-4H-chromenes ${ }^{3}$.

3. V. Jhansi Rani et. al use MSA for synthesis of 1-amidoalkyl-2-naphthols ${ }^{4}$

4. P. Kulkarni et. al use MSA for synthesis of flavanone ${ }^{5}$.

5. H. Sharghi et. al use MSA with $\mathrm{Al}_{2} \mathrm{O}_{3}$ for synthesis of monoesterification of diols ${ }^{6}$.

6. Methanesulphonic acid in combination with morpholine used as catalyst for the preparation of ylidenemalononitriles via Knoevenagel condensation of ketones with malononitrile under solvent free condition?

7. Phosphorus pentoxide-Methanesulphonic acid (Eaton's reagent) used catalyst for an expeditious, one-pot method for the synthesis of 3,4-dihydropyrimidin-2(1H)-ones under solvent free condition ${ }^{8}$.

8. Hydrofluoric acid was used as catalyst for synthesis of paracetamol from phenyl<smiles>[R]C(=O)c1ccc2ccccc2c1O</smiles>

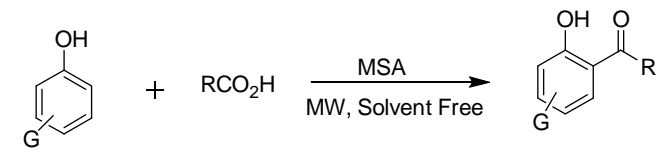
$\mathrm{R}=\mathrm{CH}_{3}, \mathrm{C}_{2} \mathrm{H}_{5}, \mathrm{C}_{3} \mathrm{H}_{7}, \mathrm{C}_{4} \mathrm{H}_{9}$ $\mathrm{G}=\mathrm{CH}_{3}, \mathrm{Br}$

Fig. 1: Direct ortho acylation of Phenol using MSA<smiles>N#CC1=C(N)Oc2c(ccc3ccccc23)C1Br</smiles><smiles>N#CC1=C(N)Oc2ccc3ccccc3c2C1Br</smiles>

4 5

Fig. 2: MSA catalyzed one-pot synthesis of 2-Amino-4H-chromenes

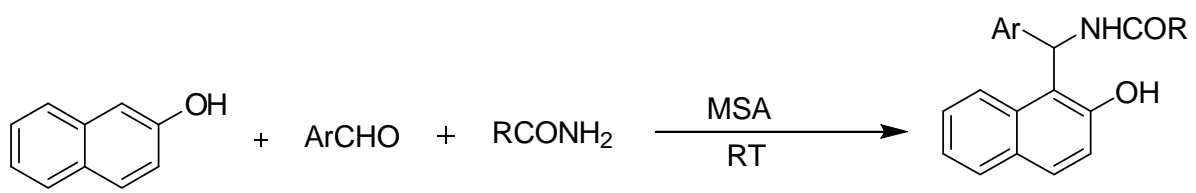

Fig. 3: Use of MSA for synthesis of 1-amidoalkyl-2-naphthols<smiles>[R2]c1cc([R1])c(C(=O)/C=C/c2cc([R6])c([R5])c([R4])c2[R3])c(O)c1</smiles>

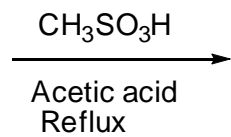<smiles>[R2]c1cc([R1])c2c(c1)OC(c1cc([R6])c([R5])c([R4])c1[R3])CC2=O</smiles>

Fig. 4: Synthesis of flavanone using MSA

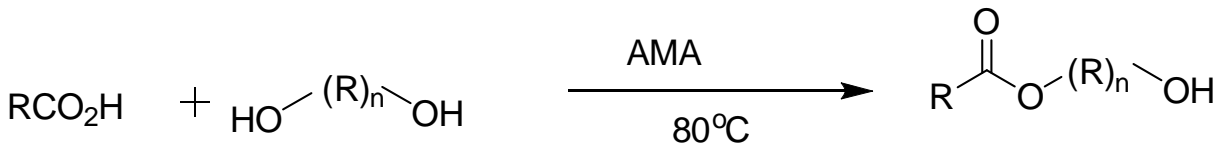

Fig. 5: Use of MSA for monoesterification of diols 
<smiles>CC(C)C1CCCC1c1cccc2ccccc12</smiles>

i $\mathrm{CH}_{2}(\mathrm{CN})_{2}$, Morpholine-MSA

9. Methane sulphonic acid used as catalyst for synthesis of 3-amino $2 \mathrm{H}$-pyrazoles prepared by reaction of $\beta$-keto nitrile with hydrazine

Fig. 6: Use of MSA in Knoevenagel condensation

acetate but tis acid is toxic and hazardous. A. Commarieua et. al uses methane sulphonic acid as a catalyst for this reaction to give para-hydroxyacetophenone with high conversion and selectivity (up to $92 \%$ of paraisomer and $8 \%$ of ortho-isomer at $100 \%$ isomer and $8 \%$<smiles>CCOC(=O)CC(C)=O</smiles><smiles>CCOC(=O)C1=C(C)NC(=O)NC1c1ccccc1</smiles>

Fig. 7: Use of $\mathrm{P}_{2} \mathrm{O}_{5} / \mathrm{MSA}$ in the synthesis of 3, 4-dihydropyrimidin-2(1H)-ones<smiles>[R]C(=O)c1ccc(O)cc1</smiles>

Fig. 8: Use of MSA in synthesis hydroxyacetophenone<smiles>[R]c1ccc(C(=O)CC#N)cc1</smiles>

Fig. 9: Use of MSA in synthesis of 3-amino-2H-pyrazoles<smiles>[R][X]c1cccc2cc[nH]c12</smiles>

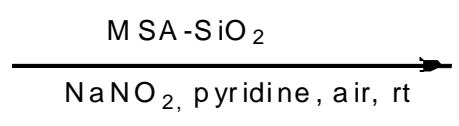<smiles>O/N=C1\C(c2c[nH]c3ccccc23)=Nc2ccccc21</smiles>

Fig. 10: Use of MSA for synthesis of (E)-2, 3'-bis(3H-indol)-3-one oxime 
under solvent and solvent free conditions ${ }^{9}$.

10. Silica-supported methane sulphonic acid used as a solid acid catalyst for three component coupling reactions of indoles and sodium nitrite to synthesize $(E)-2,3$ '-bi(3Hindol)-3-one oxime derivatives ${ }^{10}$.

11. Methane sulphonic acid on silica was used as solid support catalyst for Pechmann reaction to synthesize Coumarin ${ }^{11}$.

12. R. Reddy Leleti et. al reported isomerisation of secondary and tertiary allylic alcohols undergo 1,3-isomerization using MSA under simple and efficient conditions to afford selectively the corresponding primary Eallylic alcohols in excellent yields ${ }^{12}$.

13. M. Heravi et. al MSA used for catalyzes onepot, three component reaction of an aromatic aldehyde, malonitrile and $\alpha$ or $\beta$-naphthol to yield 2-amino-4H-chromenes in very good yields ${ }^{13}$.<smiles>[R3]c1cc([R2])c([R1])c(O)c1</smiles>

Fig. 11: Use of MSA for synthesis of Coumarin

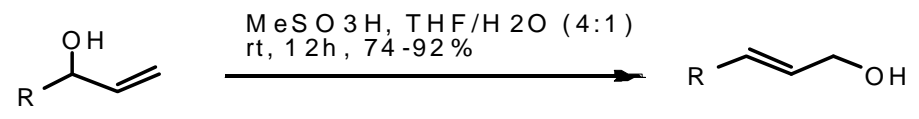

Fig. 12: Isomerization of allylic alcohols using MSA

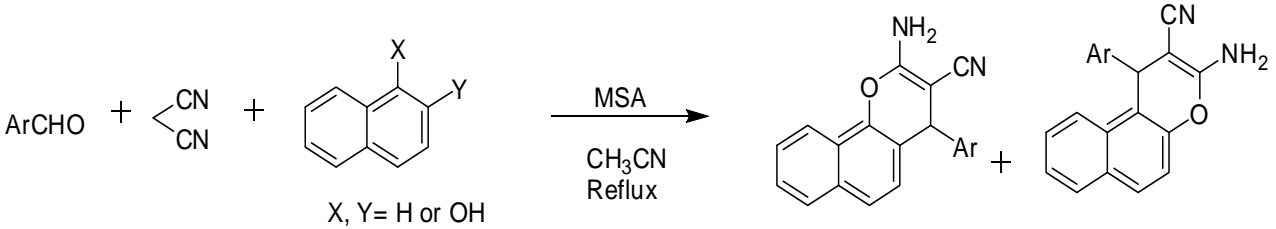

Fig. 13: MSA as a catalyst for synthesis of 2-amino-4H-chromenes

\section{REFERENCES}

1. Commarieua, A. ; Hoelderich, W.; Laffitte, J.; Dupont, M. J. Mol. Catalysis A: Chemical 2002, 182-183, 137-141.

2. Naeimi, H.; Raeisi, A.; Moradian, M. Arabian Journal of Chemistry 2013, doi: http:// dx.doi.org/10.1016/j.arabjc.2013.10.017

3. Heravi, M.; Baghernejad, B.; Oskooie, H. Journal of the Chinese Chemical Society, 2008, 55, 659-662.

4. Jhansi Rani, V.; Suresh, M.; Lavanya, P.; Vani, K.; Nagarjuna, B.; Venkata Rao, C. Der Pharma Chemica, 2010, 2, 224-230
5. Kulkarni, P.; Wagh, P.; Zubaidha, P. Chemistry Journal 20122 106-110

6. Sharghi, H.; Sarvari, M. Tetrahedron 2003, 59, 3627-3633

7. Gora, M.; Kozik, B.; Jamrozy, K.; Luczynski, M.; Brzuzan, P.; Wozny, M. Green Chemistry 2009, 11, 863-867

8. Borse, A.; Patil, M.; Patil, N.; Shinde, R. ISRN Organic Chemistry 2012, 2012, doi: 10.5402/ 2012/415645

9. Suryakiran, N. ; Reddy, T.; Asha Latha, K.; Prabhakar, P.; Yadagiri, K. Journal of 
Molecular Catalysis A: Chemical 2006, 258, 371-375.

10. Chang, Q.; Qu, H.; Qin, W.; Liu, L.; Chen, Z. Synthetic Communications 2013, 43, 29262935.

11. Joshi, J.; Mishra, M.; Srinivasarao, M. Canadian Journal of Chemistry 2011, 89,
663-670.

12. Reddy Leleti ,R.; Hu, B.; Prashad, M.; Repic, O. Tetrahedron Letters, 2007, 48, 8505-8507.

13. Heravi, M.; Baghernejad, B.; Oskooie, H. Journal of the Chinese Chemical Society, 2008, 55, 659-662. 